ORIGINAL ARTICLE

\title{
Diminished lung function, RSV infection, and respiratory morbidity in prematurely born infants
}

\author{
S Broughton, R Bhat, A Roberts, M Zuckerman, G Rafferty, A Greenough
}

Arch Dis Child 2006;91:26-30. doi: 10.1136/adc.2005.087270

See end of article for authors' affiliations

....................

Correspondence to: Prof. A Greenough, Department of Child Health, King's College Hospital, Denmark Hill, London SE5 9RS, UK; anne.greenough@ kcl.ac.uk

Accepted

24 September 2005

Published Online First

27 September 2005

\begin{abstract}
Background: Diminished lung function appears to be a risk factor for respiratory syncytial virus (RSV) infection/bronchiolitis in term born infants.

Aims: To determine if diminished lung function prior to neonatal unit discharge was associated with subsequent symptomatic RSV lower respiratory tract infection (LRTI) and respiratory morbidity in prematurely born infants.

Methods: Of 39 infants in a tertiary neonatal intensive care unit (median gestational age 28 weeks, range 23-31), 20 had bronchopulmonary dysplasia. Lung function (compliance and resistance of the respiratory system $\left(C_{r s}\right.$ and $\left.R_{r s}\right)$ and functional residual capacity (FRC)) was measured on the neonatal unit at 36 weeks postmenstrual age (PMA). Following neonatal unit discharge, nasopharyngeal aspirates were obtained on every occasion, at home or in hospital, an infant had an LRTI. RSV was identified by immunofluorescence and/or culture.

Results: The 15 infants who suffered a symptomatic RSV LRTI had a higher mean $R_{r s}$ and suffered more wheeze at follow up than the rest of the cohort. Regression analysis showed that a high $R_{r s}$ was significantly associated with a symptomatic RSV LRTI; significant factors for cough were a high $R_{r s}$ and a symptomatic RSV LRTI, and for wheeze were a high $R_{\mathrm{rs}}$.

Conclusion: Prematurely born infants, who had a symptomatic RSV LRTI and/or respiratory morbidity at follow up, had worse lung function prior to neonatal unit discharge.
\end{abstract}

$\mathrm{R}$ espiratory syncytial virus (RSV) is the most important respiratory pathogen in childhood. RSV lower respiratory tract infection (LRTI) causes acute morbidity; in the United States, it has been estimated that RSV LRTI is responsible for approximately 400000 hospital inpatient days every year in children less than 5 years of age. ${ }^{1}$ In previously healthy term born infants, it also increases the risk of asthma at follow up. ${ }^{2}{ }^{3}$ Diminished lung function, in particular small airways, may predispose to symptomatic RSV LRTI in infants born at term. ${ }^{4}$ Infants who subsequently developed bronchiolitis had a lower maximal flow at functional residual capacity $\left(\mathrm{V}_{\max } \mathrm{FRC}\right)$ at 5 weeks of age. ${ }^{4}$ In addition, in the Tucson Children's Respiratory Study, children who had at least one wheezing LRTI (44\% of which were due to RSV infection) in the first three years after birth had a lower $\mathrm{V}_{\max } \mathrm{FRC}$ prior to the LRTI. ${ }^{56}$ It is not known whether abnormal lung function predisposes prematurely born infants to symptomatic RSV LRTI, yet prematurely born infants can suffer chronic respiratory morbidity following RSV infection, ${ }^{78}$ and also are at high risk of lung abnormalities as a result of perinatal insults. ${ }^{9}$ The aim of our study, therefore, was to determine if prematurely born infants who subsequently developed a symptomatic RSV LRTI and/or respiratory morbidity at follow up had impaired lung function at 36 weeks postmenstrual age (PMA).

\section{METHODS}

Infants born prior to 32 weeks of gestational age in a single centre were eligible for entry into the study, if they delivered prior to the onset of the RSV season (thus all recruited infants would be exposed to a complete RSV season on neonatal unit discharge). The RSV season was defined as 1 October to 31 March, consistent with UK experience. ${ }^{10}$ Consecutive infants, whose parents gave informed written consent, were recruited. The Research Ethics Committee of King's College NHS Trust approved this study. The infants underwent lung function measurements at 36 weeks PMA and were followed prospectively until a corrected age of 1 year.

\section{Lung function measurements}

The infants were studied while supine and asleep; they were not sedated and none were ventilated at the time of study. Lung volume was assessed by measurement of functional residual capacity (FRC), using a commercially available helium gas dilution system (EBS 2615, Equilibrated Bio Systems, New York). The FRC system contained a $500 \mathrm{ml}$ rebreathing bag, the system reservoir, enclosed in an airtight cylinder and a helium analyser, with a real time digital display. A facemask (Rendell Baker, Laerdal, facemask size 0 or 1) was held snuggly over the infant's nose and mouth; silicone putty was used around the mask to achieve an airtight seal. The facemask was connected to the rebreathing bag via a three way valve. The three way valve was switched at the end of expiration, so that the infant subsequently breathed from the rebreathing bag. Digital display of the helium dilution curve allowed precise determination of when gas equilibration occurred. During the measurement, if there was no change in the helium concentration over a 15 second period, equilibration was deemed to have occurred. The initial and equilibration helium concentrations were used to calculate FRC, which was corrected for oxygen consumption $(7 \mathrm{ml} / \mathrm{kg} / \mathrm{min})^{11}$ and converted to body temperature and water vapour saturated conditions. FRC was measured at least twice in each infant to obtain two results which were within $10 \%$ of each other. The paired FRC results were then

Abbreviations: BPD, bronchopulmonary dysplasia; FRC, functional residual capacity; LRTI, lower respiratory tract infection; NPA, nasopharyngeal aspirate; PMA, postmenstrual age; RSV, respiratory syncytial virus 


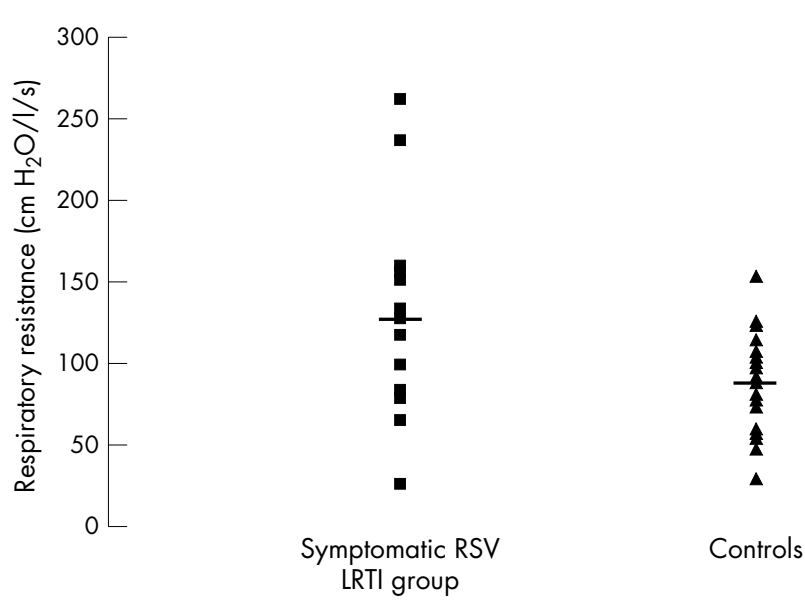

Figure 1 Scatter plot of $R_{r s}$ in the symptomatic RSV LRTI group and the controls. The solid line shows the mean value.

meaned. The mean intra-subject coefficient of variability of the measurement of the FRC was $7 \%$.

Compliance $\left(\mathrm{C}_{\mathrm{rs}}\right)$ and resistance $\left(\mathrm{R}_{\mathrm{rs}}\right)$ of the respiratory system were measured using the single breath occlusion technique. A facemask was placed over the infant's nose and mouth; silicone putty was used around the face mask to ensure an airtight seal.

A pneumotachograph (Mercury F10L; GM Engineering, Kilwinning, UK) connected to a differential pressure transducer (range: $\pm 2 \mathrm{~cm} \mathrm{H}_{2} \mathrm{O}$, MP 45, Validyne Engineering, Northridge, CA) was inserted into the facemask. The flow signal from the pneumotachograph was integrated to give volume (Validyne CD280: Validyne Engineering, Northridge, CA). From a sideport on the pneumotachograph mouth pressure was measured using a differential pressure transducer (range: $\pm 100 \mathrm{~cm} \mathrm{H}_{2} \mathrm{O}$, MP 45, Validyne Engineering, Northridge, CA). The signals were amplified (Validyne CD280: Validyne Engineering, Northridge, CA) and displayed in real time on a computer (Dell Inspiron) running Labview software (version 4.0, National Instruments, Austin, TX), with $100 \mathrm{~Hz}$ analogue to digital sampling (DAQ 16XE-50; National Instruments, Austin, TX). Occlusions were made at end inspiration, which was identified from the flow signal. The distal end of the pneumotachograph was briefly occluded; only occlusions during which there was no flow, a mouth pressure plateau of at least 100 milliseconds in duration, and a linear flow-volume plot after the occlusion were considered acceptable. $\mathrm{C}_{\mathrm{rs}}$ was calculated from the inspiratory volume and the pressure plateau and related to body weight. The time constant of the respiratory system was calculated from the linear part of the flow volume plot and $\mathrm{R}_{\mathrm{rs}}$ given by the time constant divided by the $\mathrm{C}_{\mathrm{rs}}$. The mean $\mathrm{C}_{\mathrm{rs}}$ and $\mathrm{R}_{\mathrm{rs}}$ were calculated from at least five technically acceptable occlusions and the results were then meaned. The mean intra-subject coefficients of variability of the $\mathrm{C}_{\mathrm{rs}}$ and $\mathrm{R}_{\mathrm{rs}}$ measurements were $8 \%$ and $13 \%$ respectively.

Following neonatal unit discharge, the parents were asked to contact the research team during the RSV season when their infant was symptomatic and had signs consistent with an LRTI, that is cough, wheeze, and/or shortness of breath. ${ }^{12}$ In addition, the parents were telephoned every two weeks by one of the researchers to ascertain whether the infant had been or was symptomatic. A researcher visited the home on every occasion that an infant had an LRTI and a nasopharyngeal aspirate (NPA) was obtained; NPAs were also obtained from all infants admitted to hospital with an LRTI. Immunofluorescence and culture for RSV were performed on the NPAs. Respiratory morbidity at follow up was documented by asking parents to complete diary cards for a month when their infants reached 11 months of age. They recorded on a daily basis whether their infant had cough or wheeze.

\section{Patients}

Sixty infants were eligible for inclusion into the study. Ten parents did not consent to their infants taking part in the study, a further five initially consented but then defaulted from follow up, three infants died before discharge from the neonatal unit, and unsatisfactory lung function recordings were obtained from a further three infants. The remaining 39 infants had a median gestational age of 28 (range 23-31) weeks and a birth weight of $1000 \mathrm{~g}$ (range 610-1930 g); their gestational age, birth weight, and bronchopulmonary dysplasia (BPD) status did not differ significantly from those who did not take part (data not shown). The study population consisted of 23 males (59\%). Fourteen of the mothers (36\%) had had an antenatal infection (maternal positive blood culture, histologically proven chorioamnionitis, or maternal temperature with a positive culture from a high vaginal swab and rupture of membranes of duration greater than 24 hours $\left.^{13}\right)$, and $31 \quad(79 \%)$ had received antenatal steroids. Twenty seven of the infants (69\%) had received surfactant and $20(51 \%)$ developed BPD (oxygen dependence beyond 36 weeks PMA). Nineteen (49\%) had a postnatal infection (positive blood culture or suspected clinical infection with a raised $C$ reactive protein, increased

\begin{tabular}{|llll|}
\hline \multicolumn{4}{|l|}{ Table 1 Demographics of the symptomatic RSV LRTI group and controls } \\
\hline & $\begin{array}{l}\text { Symptomatic RSV LRTI } \\
\text { group }\end{array}$ & Controls & \\
& $(\mathbf{n}=15)$ & $(\mathbf{n}=\mathbf{2 4 )}$ & p value \\
\hline Gestational age (wk) & $28(24-31)$ & $28(24-31)$ & 0.30 \\
Birth weight (kg) & $1.08(0.38)$ & $1.09(0.38)$ & 0.94 \\
Males & $10(66 \%)$ & $13(54 \%)$ & 0.26 \\
Antenatal smoking & $2(13 \%)$ & $3(12 \%)$ & 0.98 \\
Antenatal steroids & $12(80 \%)$ & $18(69 \%)$ & 0.62 \\
Surfactant & $10(66 \%)$ & $17(71 \%)$ & 0.63 \\
Duration of ventilation (days) & $6(0-30)$ & $6(0-79)$ & 0.96 \\
Bronchopulmonary dysplasia & $10(67 \%)$ & $14(58 \%)$ & 0.82 \\
Parental atopy & $5(33 \%)$ & $10(41 \%)$ & 0.96 \\
Postnatal smoking & $2(13 \%)$ & $4(16 \%)$ & 0.89 \\
Day care & $5(33 \%)$ & $4(16 \%)$ & 0.34 \\
Number of siblings & $1(0-3)$ & $1(0-4)$ & 0.67 \\
Palivizumab & $2(13 \%)$ & $4(17 \%)$ & 0.92 \\
\hline Data are shown as median (range) or $\mathrm{n}(\%)$. & & \\
\hline
\end{tabular}


Table 2 Lung function results and respiratory morbidity

\begin{tabular}{|c|c|c|c|}
\hline & $\begin{array}{l}\text { Symptomatic RSV LRTI } \\
\text { group } \\
(\mathrm{n}=15)\end{array}$ & $\begin{array}{l}\text { Controls } \\
(n=24)\end{array}$ & $p$ value \\
\hline \multicolumn{4}{|l|}{ Lung function } \\
\hline Postmenstrual age (wk) & $35.8(0.6)$ & $35.9(0.5)$ & 0.89 \\
\hline Weight $(\mathrm{kg})$ & $2.13(0.38)$ & $2.38(0.46)$ & 0.17 \\
\hline $\mathrm{FRC}(\mathrm{ml} / \mathrm{kg})$ & $21.9(4.2)$ & $21.6(3.4)$ & 0.94 \\
\hline $\mathrm{C}_{\mathrm{rs}}\left(\mathrm{ml} / \mathrm{cm} \mathrm{H} \mathrm{H}_{2} \mathrm{O} / \mathrm{kg}\right)$ & $0.98(0.47)$ & $0.99(0.52)$ & 0.82 \\
\hline $\mathrm{R}_{\mathrm{rs}}\left(\mathrm{cm} \mathrm{H} \mathrm{H}_{2} \mathrm{O} / \mathrm{l} / \mathrm{s}\right)$ & $126.1(62.1)$ & $89.1(27.8)$ & 0.01 \\
\hline \multicolumn{4}{|c|}{ Respiratory morbidity at one year } \\
\hline Cough (days/month) & $7(0-31)$ & $3(0-14)$ & 0.06 \\
\hline Wheeze (days/month) & $5(0-22)$ & $0(0-7)$ & 0.04 \\
\hline
\end{tabular}

or decreased neutrophil count, and/or decreased platelet count $\left.{ }^{14}\right)$, but none had had a nosocomial viral infection. During the study period, only infants with BPD who had required supplementary oxygen at least until one week before neonatal intensive care unit discharge and were being discharged during the RSV season were given palivizumab. As a consequence, six infants received palivizumab; two of the palivizumab group subsequently suffered a symptomatic RSV positive LRTI, but did not require hospital admission.

\section{Analysis}

The outcomes RSV infection and respiratory morbidity (cough or wheeze) at follow up were related to potential explanatory variables, which included infant, parental, and family characteristics. We chose potential explanatory variables which had been previously identified as factors which might influence RSV infection and/or respiratory morbidity in prematurely born infants. ${ }^{15-18}$ Antenatal variables recorded were antenatal infection (maternal positive blood culture, histologically proven chorioamnionitis, maternal urinary tract infection, or maternal temperature with a positive culture from a high vaginal swab and rupture of membranes of duration greater than 24 hours ${ }^{13}$ ), maternal smoking, and antenatal corticosteroid administration. Postnatal variables were sex, gestational age, birth weight, use of surfactant, postnatal infection, the number of days of mechanical ventilation, BPD, discharge from the neonatal unit between September and December, and whether the infant was bottle fed. Family variables were a family history of atopy (asthma or hay fever in a parent or sibling), the number of siblings, attendance at day care, and postnatal parental smoking. In addition the FRC, $\mathrm{C}_{\mathrm{rs}}$, and $\mathrm{R}_{\mathrm{rs}}$ results were considered as possible explanatory variables. All data were assessed for normality using the Shapiro-Wilk test for normality; normally distributed continuous variables were tested for significance using the one way ANOVA significance test (all lung function data, birth weight, gestational age, and duration of ventilation). Multiple comparisons were performed using a one way ANOVA significance test with a post hoc Bonferroni test for multiple comparisons. Nonnormally distributed were tested for statistical significance using the Mann-Whitney or $\chi^{2}$ test as appropriate. Any variable which was significant at the $p \leqslant 0.10$ level was entered into regression analysis. Binary logistic regression was used to further explore the differences between the symptomatic RSV LRTI group and the rest of the cohort controls. The controls consisted of infants who had an RSV negative symptomatic LRTI (RSV negative symptomatic LRTI) and infants who had had no symptomatic LRTI (no LRTI symptoms group). Multiple regression analysis was used to explore the relations to outcomes of cough and wheeze. Analysis was performed using SPSS version 12.0 (SPSS Inc., Chicago, IL).

\section{RESULTS}

Fifteen infants suffered at least one symptomatic RSV positive LRTI (symptomatic RSV LRTI group), six of whom required admission to hospital. The symptomatic RSV LRTI group were compared to 24 infant controls who had either a non-RSV LRTI (RSV negative symptomatic LRTI group, $\mathrm{n}=15$ ) or no LRTI symptoms (no LRTI symptoms group, $\mathrm{n}=9$ ). There were no significant differences in the demographics of the symptomatic RSV LRTI group and the controls (table 1). The two groups had similar mean FRC and $\mathrm{C}_{\mathrm{rs}}$ (tables 2 and 3), but the symptomatic RSV LRTI group had a significantly higher mean $\mathrm{R}_{\mathrm{rs}}$ at 36 weeks PMA than the controls (fig 1). Subanalysis showed that the symptomatic RSV LRTI group tended to have a higher resistance than the no LRTI symptoms group (126.1 $v$ 80.4l cm $\mathrm{H}_{2} \mathrm{O} / \mathrm{l} / \mathrm{s}$, $\mathrm{p}=0.06)$, but not the RSV negative symptomatic LRTI group ( $126.1 \vee 94.4 \mathrm{~cm} \mathrm{H}_{2} \mathrm{O} / \mathrm{l} / \mathrm{s}, \mathrm{p}=0.17$ ).

Table 3 Lung function and respiratory morbidity by RSV and LRTI status

\begin{tabular}{|c|c|c|c|c|c|}
\hline & \multirow{2}{*}{$\begin{array}{l}\text { RSV symptomatic } \\
\text { LRTI group (1) } \\
\text { ( } \mathrm{n}=15 \text { ) }\end{array}$} & \multirow{2}{*}{$\begin{array}{l}\text { RSV negative } \\
\text { symptomatic LRTI } \\
\text { group (2) } \\
(\mathrm{n}=15)\end{array}$} & \multirow{2}{*}{$\begin{array}{l}\text { No LRTI symptoms } \\
\text { group (3) } \\
(n=9)\end{array}$} & \multicolumn{2}{|l|}{$p$ value } \\
\hline & & & & $1 v 2$ & $1 \vee 3$ \\
\hline \multicolumn{6}{|l|}{ Lung function } \\
\hline Postmenstrual age (wk) & $35.8(0.6)$ & $36.0(0.7)$ & $35.8(0.9)$ & 1.000 & 1.000 \\
\hline Weight $(\mathrm{kg})$ & $2.13(0.38)$ & $2.30(0.44)$ & $2.54(0.49)$ & 0.900 & 0.091 \\
\hline $\mathrm{FRC}(\mathrm{ml} / \mathrm{kg})$ & $21.9(4.2)$ & $19.7(1.9)$ & $23.1(3.5)$ & 1.000 & 1.000 \\
\hline $\mathrm{C}_{\mathrm{rs}}\left(\mathrm{ml} / \mathrm{cm} \mathrm{H} \mathrm{H}_{2} \mathrm{O} / \mathrm{kg}\right)$ & $0.98(0.47)$ & $0.75(0.33)$ & $1.2(0.51)$ & 1.000 & 0.959 \\
\hline $\mathrm{R}_{\mathrm{rs}}\left(\mathrm{cm} \mathrm{H} \mathrm{H}_{2} \mathrm{O} / \mathrm{I} / \mathrm{s}\right)$ & $126.1(62.1)$ & $100.6(28.9)$ & 80.4 (19.9) & 0.173 & 0.058 \\
\hline \multicolumn{6}{|c|}{ Respiratory morbidity at one year } \\
\hline Cough (days) & $7(0-31)$ & $4(0-14)$ & $0(0-5)$ & 0.292 & 0.072 \\
\hline Wheeze (days) & $5(0-22)$ & $0(0-7)$ & $0(0-5)$ & 0.125 & 0.084 \\
\hline
\end{tabular}




\section{What is already known on this topic}

- Abnormal premorbid lung function, consistent with smaller airway size, appears to predispose otherwise healthy term born infants to a symptomatic RSV LRTI

Results of the diary card analysis showed that the RSV symptomatic LRTI group had more days of wheeze (median 5 (range 0-22) days) than the control group (median 0 (range $0-7)$ days $)(p=0.040)$ and tended to have more days of cough (median 7 (range 0-31) versus median 3 (range 0-14) days, $\mathrm{p}=0.056$ ). Subanalysis showed that the symptomatic RSV LRTI group did not have significantly more wheeze than the no LRTI symptoms group (median 0 (range 0-5) days, $\mathrm{p}=0.084)$ or the RSV negative symptomatic LRTI group (median 0 (range $0-7$ ) days, $\mathrm{p}=0.125$ ).

Regression analysis showed that the only factor significantly related to symptomatic RSV LRTI was a high $\mathrm{R}_{\mathrm{rs}}$ at 36 weeks PMA $(p=0.037)$ (odds ratio $1.30(1.10-1.50)$ ). Factors related to the number of days of cough were a symptomatic RSV LRTI $(\mathrm{p}<0.001)$ and a high $\mathrm{R}_{\mathrm{rs}}$ $(p=0.002)$, and to the number of days of wheeze were a high $R_{r s}(p<0.001)$ and RSV LRTI $(p=0.09)$.

\section{DISCUSSION}

We have shown that prematurely born infants who suffer a symptomatic RSV LRTI and/or had more cough and wheeze at follow up, had significantly higher resistance of the respiratory system prior to neonatal intensive care unit discharge. There were, however, no significant differences in the lung volumes or the results of compliance of the respiratory system results of the two groups. The reproducibilities of the three types of measurements were similar and thus we do not feel that the lack of significant differences in the lung volumes and compliance results reflects a type II error. Indeed, our results of a higher mean resistance in the infants who subsequently developed symptomatic RSV LRTI and respiratory morbidity are in keeping with the results found in term born infants. The high $\mathrm{R}_{\mathrm{rs}}$ we now show and the low $\mathrm{V}_{\max } \mathrm{FRC}$ previously shown ${ }^{4}$ suggest that abnormal airway function predisposes to symptomatic RSV LRTI. Our subanalysis suggests that this effect may not be specific to RSV LRTI, as the resistance results at 36 weeks PMA of the RSV LRTI and the non-RSV LRTI groups were similar $(p=0.17)$. It should, however, be emphasised that the numbers included in each subanalysis were relatively small and the observation needs further testing in a larger study.

The lung function results we report are similar to those published previously. We reported results from 20 prematurely born infants (10 with $\mathrm{BPD})$; their lung volumes measured by helium gas dilution were between 13 and $35 \mathrm{ml} /$ $\mathrm{kg}, \mathrm{C}_{\mathrm{rs}}$ between 0.4 and $1.5 \mathrm{ml} \mathrm{cm} \mathrm{H}_{2} \mathrm{O} / \mathrm{kg}$, and $\mathrm{R}_{\mathrm{rs}}$ between 87 and $194 \mathrm{~cm} \mathrm{H} \mathrm{H}_{2} \mathrm{O} / \mathrm{l} / \mathrm{s} .{ }^{19}$ In addition, Hjalmarson and Sandberg' reported that 32 prematurely born infants (none with BPD) at 40 weeks PMA had a mean (SD) $\mathrm{R}_{\mathrm{rs}}$ of 97.4 (SD 30.4) $\mathrm{cm} \mathrm{H} \mathrm{H}_{2} \mathrm{O} / \mathrm{l} / \mathrm{s}$. The similarity of the lung function results would suggest that our findings are generalisable to other populations of prematurely born infants.

We were unable to follow 21 of the eligible infants. Those not followed, however, did not differ significantly from the study population with regard to their birth weight, gestational age, or BPD status, all factors known to affect the severity of RSV infection. ${ }^{17}$ Thus, it seems unlikely that our results were biased by loss to follow up. A small number of infants received palivizumab, but it is not known whether palivizumab prevents RSV LRTI; as similar proportions in
What this study adds

- Prematurely born infants who suffered a symptomatic RSV LRTI and/or had respiratory morbidity at follow up, had significantly higher respiratory resistance at 36 weeks PMA than infants who had neither adverse outcome

each group received palivizumab, we do not feel this biased our results. Our sample was relatively small, nevertheless we identified significant differences in those who developed RSV infection and chronic respiratory morbidity.

Parents were requested to contact the research team on each occasion that their infant had a symptomatic LRTI. It is possible some parents failed to do so, but to minimise the risk of missing infants with LRTIs we also contacted the parents at two weekly intervals. The proportion of our cohort who tested positive for RSV infection (38\%) is similar to that found in a community based study of term born infants $(31.8 \%) .^{20}$ In that study ${ }^{20}$ parents were requested to contact the research team within 24 hours of their infant developing nasal stuffiness, runny nose, cough, fever, or noisy breathing; the infant was then visited and an NPA obtained. We only obtained NPAs from infants when they had signs of an LRTI and thus we cannot comment on risk factors for asymptomatic RSV infection. We were, however, keen to identify risk factors for symptomatic infection as in studies in term born infants. ${ }^{15} 1718$

In conclusion, our results suggest that abnormal airway function is associated with subsequent symptomatic RSV LRTI and cough and wheeze at follow up in prematurely born infants. The relative importance of the RSV LRTI and the premorbid diminished airway function on subsequent respiratory morbidity merits investigation.

\section{Authors' affiliations}

S Broughton, R Bhat, A Roberts, G Rafferty, A Greenough, Division of Asthma, Allergy and Lung Biology, Guy's, King's \& St Thomas' School of Medicine, King's College London, UK

M Zuckerman, Department of Virology, Guy's, King's \& St Thomas' School of Medicine, King's College London, UK

Funding: Dr Simon Broughton and Ms Alison Roberts were supported by a peer reviewed grant from the WellChild Trust and Abbott Laboratories

Competing interests: none

\section{REFERENCES}

1 Shay DK, Holman RC, Newman RD, et al. Bronchiolitis-associated hospitalizations among US children, 1980-1996. JAMA 1999;282:1440-6.

2 Noble V, Murray M, Webb MS, et al. Respiratory status and allergy nine to 10 years after acute bronchiolitis. Arch Dis Child 1997;76:315-19.

3 Sigurs N, Bjarnason R, Sigurbergsson F, et al. Respiratory syncytial virus bronchiolitis in infancy is an important risk factor for asthma and allergy at age 7. Am J Respir Crit Care Med 2000;161:1501-7.

4 Young S, O'Keeffe PT, Arnott J, et al. Lung function, airway responsiveness, and respiratory symptoms before and after bronchiolitis. Arch Dis Child 1995;72:16-24.

5 Martinez FD, Morgan WJ, Wright AL, et al. Initial airway function is a risk factor for recurrent wheezing respiratory illnesses during the first three years of life. Group Health Medical Associates. Am Rev Respir Dis $1991 ; 143: 312-16$.

6 Martinez FD, Morgan WJ, Wright AL, et al. Diminished lung function as a predisposing factor for wheezing respiratory illness in infants. N Engl J Med 1988;319:1112-17

7 Greenough A, Alexander J, Burgess S, et al. Health care utilisation of prematurely born, preschool children related to hospitalisation for RSV infection. Arch Dis Child 2004;89:673-8.

8 Greenough A, Cox S, Alexander J, et al. Health care utilisation of infants with chronic lung disease, related to hospitalisation for RSV infection. Arch Dis Child 2001;85:463-8. 
9 Hialmarson O, Sandberg K. Abnormal lung function in healthy preterm infants. Am J Respir Crit Care Med 2002; 165:83-7.

10 Clark SJ, Bereseford MW, Subhedar NV, et al. Respiratory syncytial virus infection in high risk infants and the potential impact of prophylaxis in a United Kingdom cohort. Arch Dis Child 2000;83:313-36.

11 Hey EN. The relation between environmental temperature and oxygen consumption in the new-born baby. J Physiol 1969:200:589-603.

12 Martinez FD, Wright AL, Taussig LM, et al. Asthma and wheezing in the first six years of life. The Group Health Medical Associates. N Engl J Med 1995;332:133-8

13 Schrag SJ, Zell ER, Lynfield R, et al. A population-based comparison of strategies to prevent early-onset group $B$ streptococcal disease in neonates. N Engl J Med 2002;347:233-9.

14 Fowlie PW, Schmidt B. Diagnostic tests for bacterial infection from birth to 90 days - a systematic review. Arch Dis Child Fetal Neonatal Ed 1998;78:F92-8.
15 Bulkow LR, Singleton RJ, Karron RA, et al. Risk factors for severe respiratory syncytial virus infection among Alaska native children. Pediatrics 2002;109:210-16

16 Cifuentes L, Caussade S, Villagran C, et al. Risk factors for recurrent wheezing following acute bronchiolitis: a 12-month follow-up. Pediatr Pulmonol 2003;36:316-21.

17 Joffe S, Escobar GJ, Black SB, et al. Rehospitalization for respiratory syncytial virus among premature infants. Pediatrics 1999;104(4 pt 1):894-9.

18 Lacaze-Masmonteil T, Truffert P, Pinquier D, et al. Lower respiratory tract illness and RSV prophylaxis in very premature infants. Arch Dis Child 2004;89:562-7.

19 Bhat RY, Leipala JA, Singh NR, et al. Effect of posture on oxygenation, lung volume, and respiratory mechanics in premature infants studied before discharge. Pediatrics 2003;112(1 pt 1):29-32

20 Legg JP, Hussain IR, Warner JA, et al. Type 1 and type 2 cytokine imbalance in acute respiratory syncytial virus bronchiolitis. Am J Respir Crit Care Med 2003; 168:633-9.

\section{IMAGES IN PAEDIATRICS}

doi: $10.1136 /$ adc. 2004.071225

\section{Chronic recurrent multifocal osteomyelitis is a differential of childhood limp}

n July 2004, we reviewed a 21 month old Anglo-Caribbean child who presented to our paediatric unit with a limp of his left leg. He had no history of trauma and was otherwise asymptomatic. Blood tests were normal apart from a raised erythrocyte sedimentation rate (ESR) of $15 \mathrm{~mm} / \mathrm{h}$, rising to $34 \mathrm{~mm} / \mathrm{h}$ over a four week period.

Plain radiograph of his left foot revealed an osteolytic lesion in the anterior calcaneum, which was confirmed by computed tomography (CT) scan (fig l). Examination and culture of bone biopsy specimens were negative and he improved with non-steroidal anti-inflammatory drugs (NSAIDs).

Chronic recurrent multifocal osteomyelitis (CRMO) is a rare inflammatory disorder of unknown cause characterised by periods of exacerbation interspersed by remissions. ${ }^{1}$ It primarily affects the skeletal system though extra-skeletal sites can be affected. The commonest sites are metaphyses of long bones, spine, pelvis, and shoulder girdle.

The gold standard for diagnosis of CRMO is histopathology of bony lesions. Lesions consist of chronic inflammatory cells and cultures are characteristically negative. ${ }^{2}$ Plain radiographic findings

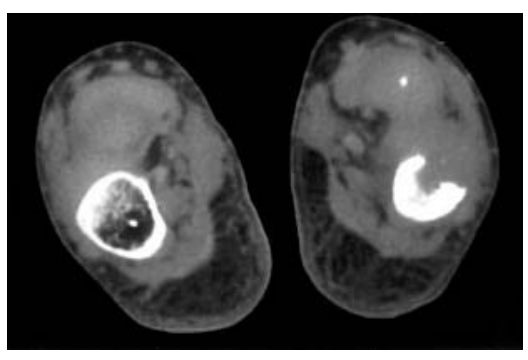

Figure 1 CT scan of the left foot showing an osteolytic lesion in the anterior calcaneum.

are variable. CRMO can present as an osteolytic, sclerotic, or a mixed lyticsclerotic lesion. Magnetic resonance imaging scans have been used to evaluate the activity of lesions and to identify the most appropriate site for biopsy. In our patient the bony lesion was confirmed by CT scan as this was more readily available.

NSAIDs are the treatment of choice. Azithromycin has been used in the treatment of this condition because of its anti-inflammatory and immunomodulatory effects. Oral steroids, bisphosphonates, and sulfasalazine have also been used in specific cases.
The long term outcome of CRMO is poorly understood. Long term sequelae include school difficulties, bony deformities, psoriasis, and inflammatory bowel disease. ${ }^{3}$

We conclude that CRMO is an important differential of childhood limp and should be considered in a persistent case of limp when other common causes have been excluded.

O Kufeji, K Withana, L Michaelis Queen Elizabeth II Hospital, Welwyn Garden City, UK

Correspondence to: Dr O Kufeji, Department of Paediatrics, Queen Elizabeth II Hospital, Welwyn Garden City, Herffordshire AL $74 Q B$, UK; o_kufeji@hotmail.com Competing interests: none

\section{References}

1 Robertson LP, Hickling P. Chronic recurrent multifocal osteomyelitis is a differential diagnosis of juvenile idiopathic arthritis. Ann Rheum Dis 2001;60:828-31.

2 Girschick HJ, Huppertz HI, Harmsen D, et al. Chronic recurrent multifocal osteomyelitis in children: diagnostic value of histopathology and microbial testing. Hum Pathol 1999;30:59-65.

3 Huber AM, Lam PY, Duffy CM, et al. Chronic recurrent multifocal osteomyelitis: clinical outcomes after more than five years of follow-up. J Pediatr 2002;141:198-203. 